\title{
Anaemia, its correlation with overweight and growth patterns in children aged 5-10 years living in American Samoa
}

\author{
Teresa M Kemmer ${ }^{1, *}$, Rachel Novotny ${ }^{2}, \mathrm{~A} \mathrm{Sam} \mathrm{Gerber}^{3}$ and laneta Ah Ping ${ }^{4}$ \\ 'Department of Nutrition, Food Science and Hospitality, South Dakota State University (SDSU), Brookings, \\ SD 57007-0497, USA: ${ }^{2}$ Department of Human Nutrition, Food and Animal Sciences, College of Tropical \\ Agriculture and Human Resources, University of Hawaii at Manoa and Director, Kaiser Permanente, Center for \\ Health Research, Honolulu, HI, USA: ${ }^{3}$ Office of Minority Health and Health Disparities, Centers for Disease \\ Control and Prevention, Atlanta, GA, USA: ${ }^{4}$ Department of Dietary Services, Lyndon B. Johnson Tropical \\ Medical Center, American Samoa, USA
}

Submitted 16 July 2007: Accepted 16 April 2008: First published online 12 June 2008

\begin{abstract}
Objectives: To determine the prevalence of anaemia, identify the predictors of anaemia, compare the prevalence of anaemia among children living in American Samoa to those found in children living in the USA, and compare the growth patterns obtained from this study to Centers for Disease Control and Prevention (CDC) data and data obtained earlier in American Samoan children.

Design: Cross-sectional.

Setting: American Samoa, a Pacific Island.

Subjects: In all, 208 children aged 5-10 years.

Results: Anaemia $(\mathrm{Hb}<11.5 \mathrm{~g} / \mathrm{dl})$ prevalence was $17 \cdot 3 \%$. There was a significant difference in mean $\mathrm{Hb}$ levels in children within American Samoa as compared to National Health and Nutrition Examination Survey III data $(P<0 \cdot 05)$. In children with BMI $Z$-score (BMIZ) $(P<0 \cdot 05)$ and weight-for-age $Z$-score (WAZ) $(P<0 \cdot 05)>2 \cdot 0$, females had a significantly higher prevalence of anaemia than males. Females with a WAZ $>2 \cdot 0$ had a significantly higher prevalence of anaemia than females with a WAZ $\leq 2 \cdot 0(P<0 \cdot 03)$. Risk factors for anaemia were mother having less than a high school education $(P=0 \cdot 02)$, no car $(P<0 \cdot 01)$ and no phone $(P=0 \cdot 02)$. The BMIZ $(P<0 \cdot 000)$, height-for-age $Z$-score $(P<0 \cdot 000)$ and WAZ $(P<0 \cdot 000)$ were significantly different from the distribution of CDC reference data and that found in children previously assessed in American Samoa.

Conclusions: Anaemia is high among children aged 5-10 years living in American Samoa. Growth pattern $Z$-scores reveal that American Samoan children are, on average, taller, heavier and more overweight. Further examination into the causes of anaemia and overweight is warranted.
\end{abstract}

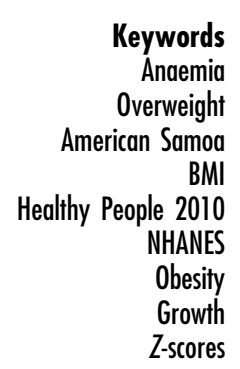

Anaemia among school-aged children is considered a public health problem and growing children are vulnerable to its consequences ${ }^{(1)}$. All clinical symptoms of iron-deficiency anaemia, including anorexia, nausea, flatulence, dimness of vision, headache, listlessness, fatigue and reduced work capacity, may have a significant impact on the performance of school-aged children ${ }^{(1)}$. In addition, school drop-out rates among school-aged children have been shown to be associated with nutritional anaemias $^{(1)}$. One of the Healthy People 2010 goals is to eliminate health disparities and the objectives include reduce the incidence of all anaemias and increase the number of people who have a healthy weight ${ }^{(2)}$. To date, the prevalence of, or factors associated with, anaemia and its relationship to weight in a representative sample of
5-10 years old children living in American Samoa have not been determined.

American Samoa is an unincorporated territory of the United States with an estimated population of 57663 and a total land area of approximately 70 square miles ${ }^{(3)}$. The present research was conducted in support of the American Samoa Health Department's essential functions of monitoring health status to identify community health problems and conduct research for new insights and innovative solutions to health problems ${ }^{(4)}$. In addition, the project was designed as a collaborative effort to obtain baseline nutritional assessment data in support of the Healthy Living in the Pacific Island (HLPI) project ${ }^{(5)}$. The objectives of the crosssectional study were to: (i) determine the prevalence of anaemia; (ii) identify anthropometric, demographic, health, 
social and economic predictors of anaemia; (iii) compare the prevalence of anaemia among children living in American Samoa to those found in children living in the USA using National Health and Nutrition Examination Survey III (NHANES III) comparison data; and (iv) compare the growth pattern $Z$-score data obtained from this study to Centers for Disease Control and Prevention (CDC) data and data obtained from an earlier study conducted in American Samoa (1978 and 1982).

\section{Participants and methods}

The study design was cross-sectional. Study participants were children, 5-10 years of age, living in American Samoa in 2003. Two-stage proportionate-to-population size cluster sampling was used for household selection, and 208 children from twenty-five American Samoan villages were evaluated. Within the selected households, one child from the appropriate age range was randomly selected to participate.

The Office of Research, Uniformed Services University of the Health Sciences, Bethesda, Maryland, and the Committee on Human Studies at the University of Hawaii, Manoa, approved this project. The data collection was coordinated through the American Samoa Department of Public Health. Through the Office of Samoan Affairs, village mayors provided coordination and approval to complete the assessments. Local team member and administrative support was provided by the Expanded Food and Nutrition Education Program, Lyndon B. Johnson Tropical Medical Center Dietary Services, Department of Public Health; the Acting Dean, Agriculture, Human and Natural Resources, American Samoa Community College and Program Manager F-4H-N; and the Secretary of Samoan Affairs.

\section{Data collection}

Data were collected at the household level via interview using a questionnaire translated to the native language. Participants had the option of being interviewed using English or the native translation of the questionnaire. The interview obtained data on child and household-specific demographic, health, social and economic factors. If more than one child in a household was within the appropriate age range, the participant was randomly selected. Written consent was obtained at the household level from one of the primary caregivers prior to data collection. In addition, children aged 7-10 years signed an assent prior to participation.

A stadiometer (Invicta Plastics Limited, Leicester, England) was used to measure child stature and weight was obtained using the UNICEF Electronic Scale 890 (Seca, Vogel \& Halke, Hammer Steindamm 9-25, Hamburg, Germany).

References from $\mathrm{CDC}^{(6)}$ were used to calculate BMIfor-age $Z$-score (BMIZ), height-for-age Z-score (HAZ), and weight-for-age $Z$-score (WAZ). Growth pattern data collected by J. Bindon and his team from children aged 6-10 years living in American Samoa in 1978 and 1982 ${ }^{(7)}$ were used to compare BMIZ, WAZ and HAZ distribution to data obtained in the present study.

$\mathrm{Hb}$ concentration was used to assess anaemia ${ }^{(8)}$. Rapid evaluation of anaemia was conducted in the household using the HemoCue Blood Hemoglobin Photometer (HemoCue, Angelholm, Sweden). Anaemia was diagnosed using the WHO age-specific cut-off $\mathrm{Hb}$ values of $<11.5 \mathrm{~g} / \mathrm{dl}$ (children aged 5-11 years) ${ }^{(9)}$. Anaemia status and $\mathrm{Hb}$ results from American Samoan children aged 5-10 years were compared to data from children of the same age range collected during NHANES III. Within the NHANES III data set, Hb was available for 2776 children aged 5-10 years.

\section{Statistical analysis}

Statistical analyses were completed using the Statistical Package for the Social Sciences (SPSS, Chicago, IL, USA) version 12.0.1 and EPINUT in Epi Info 2000 (CDC, Atlanta, GA, USA). Descriptive statistics were completed and histograms were used to visually determine the normality of the distributions. Relative risk was used to describe the ratio of the risk attributable to anaemia. Participant data were stratified into dichotomous groups and analysed using joint contingency tables followed by $\chi^{2}$ statistics. Using the anaemia cut-off value of $\mathrm{Hb}<$ $11.5 \mathrm{~g} / \mathrm{dl}$, logistic regression was used to determine the relationships between anaemia and the variables of interest. One-sample $t$ test and $t$ test for two independent samples were completed. Data analysis was completed at the $95 \%$ level to determine significance. Data are presented as mean (SD).

\section{Results}

\section{Demograpbics}

The mean age of children ( $n$ 208) was $7 \cdot 3$ (SD $1 \cdot 5)$ years (range 5.0-9.9 years) and $49 \%$ were female. The percentage of children classified as $100 \%$ Samoan as reported by their guardian was $82 \%$. An additional $10 \%$ had one parent who was $100 \%$ Samoan. Thus, all children were at least $50 \%$ Samoan. Mean birth weight was 3.50 (SD 0.60) kg (range $1 \cdot 82-6 \cdot 14 \mathrm{~kg}$ ). Reported father literacy rate was $95 \%$ and mother literacy was greater than 99\%. Of the fathers, $91 \%$ had at least a high school education and $28 \%$ were educated beyond high school. Similarly, 94\% of the mothers had at least a high school education and 33\% were educated beyond high school. Households were typically large, with $60 \%$ having seven or more family members living together.

The following items were used as economic indicators: $99 \%$ of the families had electricity, $94 \%$ a television, $88 \%$ a radio, $85 \%$ a telephone, $83 \%$ a refrigerator, $81 \%$ an 
indoor toilet and $63 \%$ a car. Reported annual household income was less than $\$ 25000$ in $67 \%$ of the households and less than $\$ 10000$ in $35 \%$.

Children eating breakfast and lunch at school were 96\%. Within the children surveyed, 85\% participated in physical activity at school, 50\% participated at least three times per week and $18 \%$ were on at least one sports team. Of the children, $50 \%$ watched one hour or more of television on school days and $75 \%$ on weekends. In $67 \%$ of the households, at least one individual smoked cigarettes.

\section{Anaemia in children living in American Samoa}

Anaemia prevalence for pre-adolescent children (5-10 years) living in American Samoa was $17 \cdot 3 \%$ ( $n$ 208). The prevalence of anaemia by age is shown in Fig. 1 . Mean $\mathrm{Hb}$ was $12 \cdot 49($ SD $1 \cdot 13) \mathrm{g} / \mathrm{dl}$; range $9 \cdot 3-15 \cdot 2 \mathrm{~g} / \mathrm{dl}$. Mean Hb by age category is shown in Table 1 . Mean $\mathrm{Hb}$ by gender was $12.54(\mathrm{SD} 1 \cdot 11) \mathrm{g} / \mathrm{dl}$ for males and 12.44 (SD 1.15) g/dl for females. There was no significant difference in prevalence of anaemia between age category or gender.

Positive predictors of anaemia, determined by $\chi^{2}$ analysis, included the following: mother not having a high school education $(P=0 \cdot 02)$, no car $(P \leq 0 \cdot 01)$ and no phone $(P=0 \cdot 02)$. As determined by relative risk assessment, children were $2 \cdot 6$ times more likely to have anaemia if their mother had not completed high school,
$2 \cdot 3$ times more likely if they had no car and $2 \cdot 2$ times more likely if they had no phone. A logistic regression model for predictors of anaemia yielded the family having no car as the only significant variable $(P<0 \cdot 005 ; 95 \%$ CI $0 \cdot 16,0 \cdot 69)$. Age, gender, weight, parental education and literacy, and diarrhoea, vomiting or fever within the last $7 \mathrm{~d}$ were not associated with anaemia in the model.

\section{Anaemia in children living in American Samoa compared to NHANES data}

Comparing children living in American Samoa with children of similar ages using NHANES III data, children living in American Samoa had significantly lower mean $\mathrm{Hb}$ levels $(P=0 \cdot 3)$. There was a significant difference between females $(P<0 \cdot 05)$ but no difference between males. The only significant difference found between ages was in 9-year-olds $(P<0 \cdot 001)$. Anaemia prevalence differences between children living in American Samoa and the children living within the US mainland are shown in Fig. 1.

\section{Growth patterns as compared to $C D C$ reference standards}

Mean (SD) BMIZ, HAZ and WAZ by age category are shown in Table 1 . There were no significant gender differences for mean HAZ, WAZ and BMIZ. Mean BMIZ $(P<0 \cdot 000)$, HAZ $(P<0 \cdot 000)$ and WAZ $(P<0 \cdot 000)$, as a whole and by gender, were significantly different in

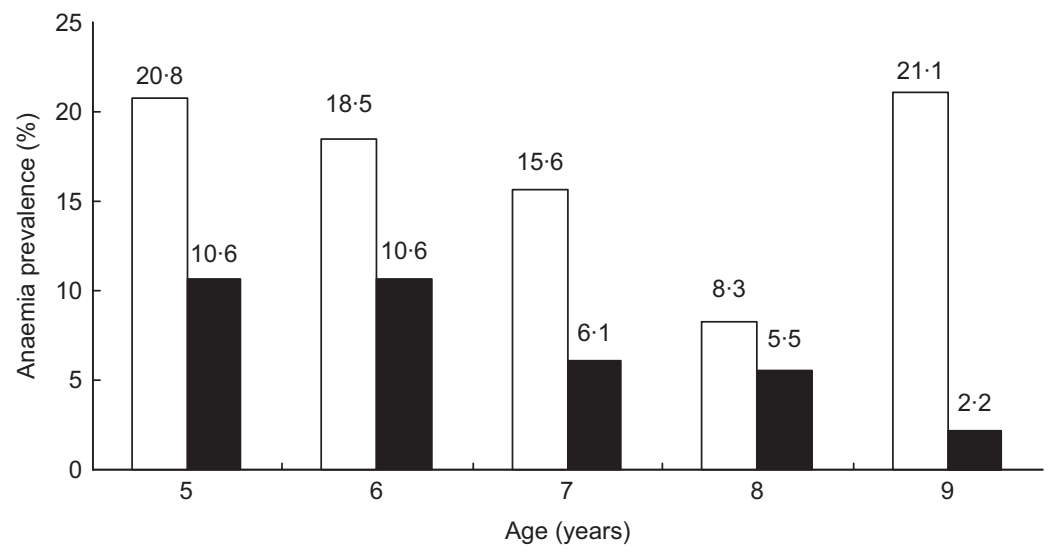

Fig. 1 Prevalence of anaemia $(\mathrm{Hb}<11.5 \mathrm{~g} / \mathrm{dl})$ in children aged $5-10$ years living in American Samoa ( $n$ 208) as compared to US children ( $n$ 2776) using data from the Third National Health and Nutrition Examination Survey (NHANES III) ( $\square$, American Samoa; 口, NHANES III)

Table 1 Percentage of children within each age category, and mean $\mathrm{Hb}$ and BMI-for-age, height-for-age and weight-for-age $Z$-score levels ( $n$ 208)

\begin{tabular}{|c|c|c|c|c|c|c|c|c|c|c|}
\hline \multirow[b]{2}{*}{ Age (years) } & \multicolumn{2}{|c|}{ Percentage of children by age } & \multicolumn{2}{|c|}{$\mathrm{Hb}(\mathrm{g} / \mathrm{dl})$} & \multicolumn{2}{|c|}{ BMIZ } & \multicolumn{2}{|c|}{$\mathrm{HAZ}$} & \multicolumn{2}{|c|}{ WAZ } \\
\hline & $n$ & $\%$ & Mean & SD & Mean & SD & Mean & SD & Mean & SD \\
\hline 5 & 48 & 23 & $12 \cdot 19$ & 1.07 & 1.00 & 0.90 & 0.69 & $1 \cdot 12$ & 0.95 & 1.05 \\
\hline 6 & 54 & 26 & $12 \cdot 58$ & $1 \cdot 29$ & $1 \cdot 10$ & 1.07 & 0.94 & $1 \cdot 26$ & $1 \cdot 24$ & $1 \cdot 27$ \\
\hline 7 & 32 & 16 & $12 \cdot 62$ & 1.05 & 1.05 & 1.05 & 0.59 & $1 \cdot 30$ & $1 \cdot 10$ & 1.31 \\
\hline 8 & 36 & 17 & $12 \cdot 73$ & 0.92 & 0.73 & 0.97 & 0.46 & 1.07 & 0.79 & 1.05 \\
\hline 9 & 38 & 18 & $12 \cdot 39$ & $1 \cdot 17$ & $1 \cdot 21$ & 0.94 & 0.73 & $1 \cdot 22$ & $1 \cdot 27$ & $1 \cdot 10$ \\
\hline
\end{tabular}

n, number of subjects; BMIZ, BMI-for-age Z-score; HAZ, height-for-age Z-score; WAZ; weight-for-age Z-score. 


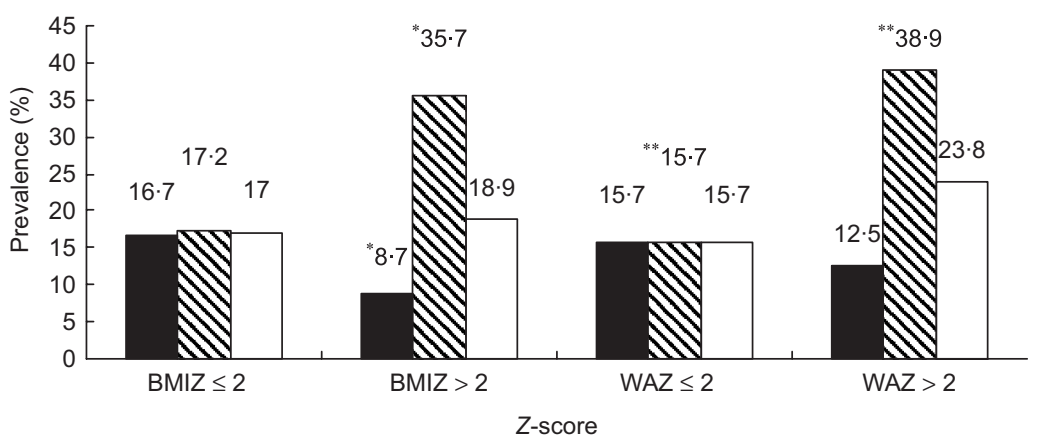

Fig. 2 Prevalence of anaemia within the American Samoan children by BMI-for-age and weight-for-age $Z$-score categories ( $n$ 208) (BMIZ, BMI-for-age Z-score; WAZ, weight-for-age Z-score). ${ }^{*} F e m a l e s$ with BMIZ and WAZ $>2 \cdot 0$ had a significantly higher prevalence of anaemia than males $(P<0 \cdot 05) .{ }^{*}$ Females with a WAZ $>2 \cdot 0$ had a significantly higher prevalence of anaemia than females with a WAZ $\leq 2 \cdot 0(P<0.03)$ ( $\mathbf{\square}$, male; $\mathbf{\nabla}$, female; $\square$, both genders)

American Samoan children compared to the CDC reference population ${ }^{(6)}$.

\section{Anaemia and its relationship to overweight in American Samoan children}

The prevalence of anaemia within children by BMIZ and WAZ categories $\leq 2 \cdot 0$ and $>2 Z$-scores is shown in Fig. 2. The cut-off value of $2 \cdot 0 Z$-scores was selected since a child in a particular population is regarded as overweight if between $2 \cdot 0$ and 4.0 standard deviations of that population ${ }^{(10)}$. When evaluating anaemia prevalence in all children, there was no significant difference between children with $\leq 2.0$ or $>2.0$ BMIZ or WAZ. In children with BMIZ $(P<0 \cdot 05)$ and WAZ $(P<0.05)>2 \cdot 0$, females had a significantly higher prevalence of anaemia than males. Females with a WAZ $>2 \cdot 0$ had a significantly higher prevalence of anaemia than females with a WAZ $\leq 2 \cdot 0(P<0 \cdot 03)$. There was a significant interaction between gender and weight (WAZ) as a predictor of anaemia $(P<0 \cdot 05)$.

\section{Growth pattern changes within the children living in American Samoa since 1978}

Mean (SD) BMIZ, WAZ and HAZ distribution comparing children aged 6-10 years living in American Samoa assessed within the present study conducted in 2003 and the data collected by J. Bindon and his team in 1978 and $1982^{(7)}$ within children of the same age range compared with the CDC reference population are shown in Fig. 3a-c. There was a significant difference $(P<0 \cdot 000)$ between mean BMIZ, WAZ and HAZ data obtained from the two studies. Comparing data obtained in our study with data collected in 1978 and $1982^{(7)}$, height and weight patterns of American Samoan children are shifting to the right.

\section{Discussion}

\section{Anaemia}

The unmet need for iron in times of rapid growth, during infancy, early childhood, adolescence and pregnancy, results in iron-deficiency anaemia and iron deficiency. In addition, poor dietary iron intake, especially of bioavailable iron, and helminth infections such as hookworms result in iron deficiency and anaemia ${ }^{(11)}$. Iron deficiency is the most common nutritional cause of anaemia but it is essential to recognise that multiple nutrient deficiencies may be present ${ }^{(12)}$.

The prevalence of anaemia within this sample of American Samoan children was $17 \cdot 3 \%$. Results from US data obtained in 1988-94 through NHANES III ${ }^{(13)}$ revealed the prevalence of anaemia in children aged 6-8 years to be $4.5 \%$ and within children aged 9-11 years, $1.0 \%$. In comparison, prevalence of anaemia in children aged 6-8 living in American Samoa was 18.7\% and in children aged 9-10 it was $14 \cdot 9 \%$. Prevalence of anaemia from NHANES II (1976-80) for all races and Caucasians ages $6-8$ years was $2 \cdot 3 \%$ and $1 \cdot 5 \%$, respectively, and for ages 9-11 years it was $2 \cdot 8 \%$ and $2 \cdot 5 \%$, respectively, with the lowest prevalence of anaemia in children aged 6-8 years ${ }^{(14)}$. The Washington State component of the Ten State Nutritional Survey conducted in 1968-71 reported anaemia prevalence of $10.8 \%$ and a median value of $12 \cdot 9 \mathrm{~g} / \mathrm{dl}$ among children aged $5-11$ years ${ }^{(15)}$. NHANES data show the progress made within the USA on decreasing the prevalence of anaemia over time ${ }^{(14,16)}$. American Samoa, as a US territory, could be expected to have comparable anaemia prevalence levels, but instead they are considerably higher.

In a study of Marshallese children, using the WHO cut-off values for anaemia, $13.8 \%$ of children aged 6-8 years and $9 \cdot 1 \%$ of children aged 9-11 years were determined to be anaemic ${ }^{(17)}$. In comparing the Marshallese children with American Samoan children, the prevalence of anaemia was higher in the American Samoan children for all age categories with the exception of 8-year-olds.

Values derived from NHANES III (1988-94) showed a mean $\mathrm{Hb}$ of 13.09 (SD 7.92) $\mathrm{g} / \mathrm{dl}^{(16)}$ for all children aged 6-11 years and was similar to the findings of Harmatz et al. ${ }^{(12)}$. Both report mean $\mathrm{Hb}$ levels greater than those 

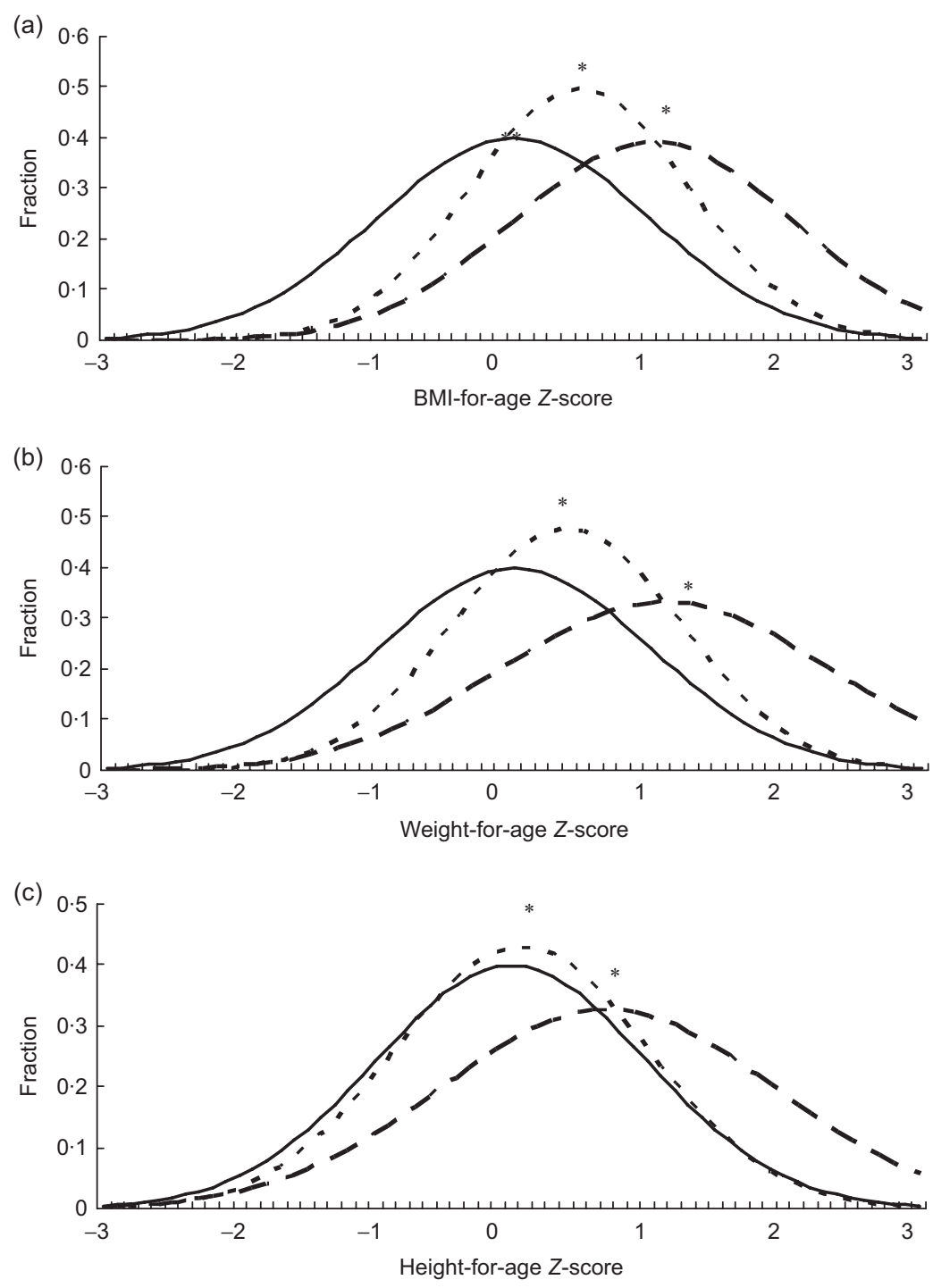

Fig. 3 (a) BMI-for-age Z-scores of American Samoan children aged 6-10 years from two studies, $†$, $\neq$ compared to Centers for Disease Control and Prevention (CDC) reference data. †Reference data set from Bindon and Zansky collected in 1978 and 1982 (1986) ${ }^{(7)}$; $n$ 228; Mean 0.49, sD 0.93. $¥ 2003$ data: $n$ 160; Mean 1.03, SD 1.02. *Statistically different $(P<0 \cdot 000)$. (b) Weight-for-age Z-scores of American Samoan children aged 6-10 years from two studies, †, $\neq$ compared to CDC reference data. †Reference data set from Bindon and Zansky collected in 1978 and $1982(1986)^{(7)} ; n$ 228; Mean 0.38, SD 0.84. $\ddagger 2003$ data: $n$ 160; Mean 1·12, SD 1·20. *Statistically different $(P<0 \cdot 000)$. (c) Height-for-age $Z$-scores of American Samoan children aged 6-10 from two studies, †, $\ddagger$ compared to CDC reference data. †Reference data set from Bindon and Zansky collected in 1978 and $1982(1986)^{(7)} ; n$ 228; Mean 0.07, SD 0.93. $\ddagger 2003$ data: 160; Mean 0.71 , SD 1.22. *Statistically different $(P<0.000)(\longrightarrow$, Theoretical Z-score distribution; - - - - , 1978; $-1,2003)$

found within the children living in American Samoa, $12 \cdot 49(\mathrm{SD} 1 \cdot 13) \mathrm{g} / \mathrm{dl}$.

\section{Growth patterns as compared to $C D C$ reference standards}

Maintaining a healthy weight should begin in early childhood and Healthy People 2010 Leading Health Indicators include reducing the proportion of children and adolescents who are overweight or obese ${ }^{(2)}$. Populations progressing socio-economically are presenting with diseases of excessive food consumption, which are affecting a growing number of children ${ }^{(18)}$. The HAZ (mean $0 \cdot 65$, SD $1 \cdot 11$ ), BMIZ (mean $1 \cdot 01$, SD 0 98) and WAZ (mean $1 \cdot 06$, SD $1 \cdot 15)$ of American Samoan children were significantly different $(P<0 \cdot 000)$ from the CDC reference population (mean 0 and SD 1 ) distribution. This demonstrates that when compared to the reference population distribution, American Samoan children are, on average, taller, heavier and more overweight.

\section{Growth pattern changes witbin the children living} in American Samoa since 1978

When the present growth pattern was compared to that obtained from children of the same ages in 1978 and 1982 
(Fig. 3a-c), the mean BMIZ, WAZ and HAZ were all statistically different. This reveals that children in 2003 had a higher BMI, were taller and weighed more than children assessed in 1978 and 1982. Prior to outside influences, Pacific Islanders living in the traditional manner were robust, physically fit, active and relatively free of nutritional deficiencies or disorders and their remoteness helped protect them from diseases inherent to other parts of the world; however, in modern times their health risks are some of the highest in the world ${ }^{(19)}$.

\section{Health}

During the school year, $96 \%$ of the children reported participation in the school breakfast and lunch programmes. With a potentially significant portion of a child's daily energy consumption provided from meals consumed at school, it is essential that schools and communities share the responsibility of providing all students with access to highquality meals and school meal plans should contribute to dietary patterns consistent with the Dietary Reference Intakes ${ }^{(20)}$. New US school board state legislature policies are aimed at establishing nutrition standards for beverages and foods sold in schools ${ }^{(21)}$; it would be beneficial to consider these policies in American Samoa.

A previous study, conducted to assess the diet of American Samoan children, found that energy intakes of the children were low, in addition to the reported intakes of calcium, phosphorus, iron, thiamin and riboflavin; however, it was concluded that with the potential exception of iron deficiency, the low reported intakes of most of these nutrients were not supported by clinical symptoms of undernutrition $^{(22)}$. Since the current study found a high prevalence of anaemia, further studies should clarify that iron deficiency is indeed the cause, and factors leading to it. Increased dietary intakes of foods high in iron such as meats and iron-fortified foods, or iron supplements, if medically indicated, should be promoted ${ }^{(23)}$.

No health status indicators from the present survey were predictors of anaemia. Helminth infestations can result in iron deficiency and anaemia; however, neither filariasis nor helminth diagnosis or treatment, within the last 6 months as reported by the caregiver, were associated with anaemia in this study. A study conducted in children aged 5-12 years living within the Pacific Islands in 2001-2002 also found no association between helminth infection and anaemia ${ }^{(24)}$. The American Samoa Department of Public Health is participating in the WHO Filariasis Campaign to control filariasis and helminthes. Therefore, helminth infection does not appear to be the primary cause for the high prevalence of anaemia within this population.

Physical activity is a Healthy People 2010 Leading Health Indicator. One of the objectives is to increase the proportion of adolescents who engage in vigorous activity that promotes cardiorespiratory fitness 3 or more days per week for 20 or more minutes per occasion ${ }^{(2)}$. Within this study, $85 \%$ of the children participated in physical activity at school. Increased physical activity is another important strategy to prevent and control overweight.

Within American Samoan children, aged 5-10 years, assessed within this study, the prevalence of anaemia was very high at $17 \%$ compared to US children from NHANES III. Lower level of mother's education and economic indicators were associated with a higher risk of anaemia. The mean BMIZ, WAZ and HAZ are high when compared to CDC reference data and to children of the same age range living in American Samoa assessed in 1978 and 1982. Effective child health initiatives will require leadership, strong health systems, targeted human and financial resources, and modifications to existing health systems ${ }^{(25)}$.

The actual cause of anaemia within this population cannot be determined without additional biochemical analysis and future research initiatives should incorporate specific analysis to determine the iron status. Since obesity can also result in immunosuppression, infectious and non-infectious morbidity should be evaluated. In addition, detailed dietary intake including school meals should be evaluated along with determining of actual helminth infection.

The challenge of combating anaemia is in understanding how to implement effective and sustainable interventions ${ }^{(26)}$. In American Samoa, local leaders and medical professionals will need to determine best practices for the region. Suggestions for clinical practice would be to incorporate the CDC recommendation for children aged 5-12 years, which includes screening for anaemia in children with low iron intake, special healthcare needs and a history of iron deficiency anaemia ${ }^{(27)}$. Primary prevention strategies need to be designed and tested and an adequate investment in resources are required to establish effective treatment plans ${ }^{(28)}$. The results derived from this study provide a foundation for health policy, health promotion, programme implementation and on-going evaluation emphasising dietary adequacy and weight management to ensure health and nutrition initiatives for pre-adolescent children living in American Samoa are met.

\section{Acknowledgements}

Funding source: The project was funded primarily by the Office of Minority Health, Centers for Disease Control and Prevention and the Henry M. Jackson Foundation for the Advancement of Military Medicine through the Center for Disaster and Humanitarian Assistance Medicine, with additional funding provided through USDA/ADAP grant no. 00-38826-9180.

Conflict of interest: No conflicts of interest or financial interests are declared.

Author contributions: T.K. contributed to the concept and design, obtained funding, conducted the study, analysed and interpreted the data and drafted the manuscript. R.N. contributed to the concept and design, 
obtained funding, assisted with training and conducting of the study, provided recommendations about the interpretation of data analysis and contributed to writing the manuscript. A.S.G. assisted with project coordination and data collection. I.A. contributed to coordination and conduct of the study and critical revision of the article for important intellectual content.

Acknowledgements: Nicky Davison, Project Administrator, Healthy Living in the Pacific Islands Project, University of Hawaii-Manoa, provided project coordination assistance. Geraldine Perry, PhD, Division of Adult and Community Health, National Center for Chronic Disease Prevention and Health Promotion, CDC, provided consultation for the anaemia assessment. James Bindon, PhD, Department of Anthropology, University of Alabama, allowed the use of growth pattern data previously collected within children living in American Samoa during 1978 and 1982 for comparison.

Disclaimer: This work was performed at the Uniformed Services University of the Health Sciences, Bethesda, MD, USA. The views expressed in this manuscript are those of the authors and do not reflect the official policy of the Department of Army, Department of Defense or US Government.

\section{References}

1. Passi SJ \& Vir SC (2001) Functional consequences of nutritional anemia in school age children. In Nutritional Anemias, pp. 89-109 [U Ramakrishnan, editor]. Washington, DC: CRC Press.

2. US Department of Health and Human Services (2000) Healthy People 2010. With Understanding and Improving Health and Objectives for Improving Health, 2nd ed. Washington, DC: US Government Printing Office.

3. Central Intelligence Agency (2008) The World Fact BookAmerican Samoa. http://www.cia.gov/library/publications/ the-world-factbook/geos/aq.html

4. American Samoa Government Department of Health (2008) http://americansamoa.gov/departments/depts/health.htm

5. Secretariat of the Pacific Community (2008) Public Health Programme Healthy Pacific Lifestyle. http://www. spc.int/AC/Healthy_Lifestyle/regional_organisations.html

6. National Center for Health Statistics (2000) 2000 CDC Growth Charts: United States. http://www.cdc.gov/ GROWTHCHARTS/

7. Bindon JR \& Zansky SM (1986) Growth patterns of height and weight among three groups of Samoan preadolescents. Ann Human Biol 13, 171-178.

8. Centers for Disease Control and Prevention (1998) Recommendations to prevent and control iron deficiency in the United States. MMWR Recomm Rep 47, 1-29.

9. United Nations Children's Fund (1998) Preventing Iron Deficiency in Women and Children: Background and Consensus on Key Technical Issues and Resources for
Advocacy, Planning and Implementing National Programmes. Paper presented at the UNICEF/UNU/WHO/MI Technical Workshop, UNICEF, New York.

10. Bergstrom E \& Hernell O (2001) Obesity and insulin resistance in childhood and adolescence. In Primary and Secondary Preventive Nutrition, pp. 165-184 [A Bendich and RJ Deckelbaum, editors]. Totowa, NJ: Humana Press.

11. Yip R (2001) Iron deficiency and anemia. In Nutrition and Health in Developing Countries, pp. 327-342 [R Semba and $\mathrm{M}$ Bloem, editors]. Totowa, NJ: Humana Press.

12. Harmatz P, Butensky E \& Lubin B (2003) Nutritional anemias. In Nutrition in Pediatrics: Basic Science and Clinical Application, pp. 830 [WA Walker, JB Watkins and C Duggan, editors]. London: BC Decker Inc.

13. Hollowell J, Van Assendelft O, Gunter E et al. (2005) Hemotological and Iron-Related Analytes-Reference Data for Persons Aged 1 Year and Over: United States, 1988-1994. Vital Health Statistics, vol. 11, p. 247. Hyattsville, MD: National Center for Health Statistics.

14. Dallman PR, Yip R \& Johnson C (1984) Prevalence and causes of anemia in the United States, 1976 to 1980. Am J Clin Nutr 39, 437-445.

15. Cook JD, Finch CA \& Smith NJ (1976) Evaluation of the iron status of a population. Blood $\mathbf{4 8}, 449-455$.

16. Looker AC, Dallman PR, Carroll MD, Gunter EW \& Johnson CL (1997) Prevalence of iron deficiency in the United States. JAMA 277, 973-976.

17. Dungy CI, Morgan BC, Heotis PM, Branson HE \& Adams WH (1987) Normal hemotologic values and prevalence of anemia in children living on selected Pacific Atolls. Acta Haematol 77, 95-100.

18. Cavalli-Sforza L, Rosman A, de Boer A \& Darnton-Hill I (1996) Nutritional aspects of changes in disease patterns in the Western Pacific Region. Bull World Health Organ 74, 307-318.

19. Coyne T (2000) Lifestyle Diseases in Pacific Communities. New Caledonia: Secretariat of the Pacific Community.

20. American Dietetic Association (2004) Position of the American Dietetic Association: dietary guidance for healthy children ages 2 to 11 years. J Am Diet Assoc 104, 660-677.

21. Institute of Medicine (2005) Preventing Childhood Obesity. Washington, DC: The National Academies Press.

22. Bindon J (1994) Some implications of the diet of children in American Samoa. Coll Anthropol 18, 7-15.

23. National Academy of Sciences (2002) Dietary Reference Intakes for Vitamin A, Vitamin K, Arsenic, Boron, Chromium, Copper, Iodine, Iron, Manganese, Molybdenum, Nickel, Silicon, Vanadium and Zinc. Washington, DC: National Academy Press.

24. Hughes R, Sharp D, Hughes M et al. (2004) Environmental influences on helminthiasis and nutritional status among Pacific schoolchildren. Int $J$ Environ Health Res 14, 163-177.

25. Bellagio Study Group on Child Survival (2003) Knowledge into action for child survival. Lancet 362, 323-327.

26. Nantel G \& Tontisirin K (2002) Supplement: forging effective strategies to combat iron deficiency. J Nutr 132, 839S-844S.

27. Morey SS (1998) CDC issues guidelines for prevention, detection and treatment of iron deficiency. Am Fam Physician 58, 1475-1477.

28. Committee on Nutrition (2003) Prevention of pediatric overweight and obesity. Pediatrics 112, 24-430. 